\title{
Aspectos a considerar de la política exterior de Juan Manuel Santos
}

\author{
Entrevista a Luis Fernando Vargas-Alzate \\ Vicepresidente de la RedIntercol \\ Profesor Asistente, Universidad EAFIT
}

Por Jennifer García

Estudiante de Ciencia Política con énfasis en Relaciones Internacionales (jennifer_garciaq@hotmail.com)

Desde su llegada a la presidencia, Juan Manuel Santos ha emprendido una serie de cambios a la política exterior colombiana, los cuales se reflejan en asuntos como la diversificación de las relaciones internacionales del país, el fortalecimiento de la cooperación Sur - Sur, el tema de la noconfrontación, entre otros. En el marco de un posible escenario de pos-conflicto, surgen las siguientes preguntas:

Jennifer García (JG): ¿Cómo se puede caracterizar la política exterior colombiana en el gobierno de Juan Manuel Santos?

\section{Luis Fernando Vargas-Alzate} (LFVA): En general, podría decirse que la política exterior colombiana
(PEC) de la última administración ha estado orientada a un proceso de recomposición de los vínculos con la región latinoamericana. Si bien la PEC continúa careciendo de institucionalidad y, a partir de su aplicación, se considera aún fragmentada y con profundos visos de política de gobierno, es real que el ejercicio internacional del país muestra mejores resultados en los últimos cuatro años, que en la administración liderada por el presidente Uribe Vélez.

Dentro de una caracterización de las relaciones internacionales del país para la administración Santos, también habría que mencionar que se presentó un leve 


\section{"Mientras se siga dependiendo de las decisiones de unos pocos, que además resultan ser decisiones tomadas bajo la presión e incidencia de élites dominantes, las relaciones internacionales del país no van a evolucionar lo suficiente como para permitir algún relativo protagonismo regional, $n i$ mucho menos global"}

distanciamiento de Washington -sin que ello haya afectado la bilateralidad con el país del Norte- y un acercamiento a otras regiones tradicionalmente desplazadas por las prioridades estadounidenses. Europa ha cobrado importancia y Asia Pacífico sigue estando entre las prioridades del país. En relación con esa última región, el hecho de haberle apostado con fuerza a la consolidación de la Alianza del Pacífico es un indicador más de cuánto importa esa región al país.

JG: ¿Cree usted que la "internacionalización del conflicto armado" continuará siendo una dinámica predominante en los próximos años del gobierno de Santos, en un posible escenario de pos-conflicto?

LFVA: Dadas las circunstancias en las que se mueve el país, el conflicto armado sí va a permanecer como dinámica predominante en la internacionalización del país, pues no está tan claro que en menos de doce meses se haya llegado a un punto de finalización de los diálogos que se desarrollan en la Habana. Ahora bien, con ello lo que se quiere resaltar es que el escenario de pos-conflicto no está tan cercano como desde algunos meses, en tiempos de procesos electorales, se había transmitido. La finalización de los diálogos, con lo que significa dejar ter- 
minado el documento que deberá ser refrendado por la opinión pública nacional e internacional, no es un asunto que se pueda dejar superado en 2015. Los tiempos de las FARC son muy diferentes a los tiempos del Estado.

JG: A partir de lo anterior, ¿cuáles son los principales desafíos que tiene el actual presidente de Colombia en términos de política exterior?

LFVA: Existen varios desafíos para la actual administración, pero uno de ellos, indudablemente, está relacionado con una estrategia que sea útil para atenuar la importancia que ha tenido el conflicto armado en temas de relaciones internacionales y cooperación internacional. Se perciben importantes esfuerzos por parte del actual gobierno para lograr que otras variables, factores y procesos sean más atractivos, relevantes y pertinentes que el solo tema del conflicto armado interno que ha tenido el país por décadas. No obstante, es obvio que eso resulta inevitable, máxime cuando hay terceros países que actúan como garantes del proceso en mención.

Al gobierno nacional le corresponde seguir trabajando ajustado a las directrices trazadas en el plan nacional de desarrollo 2010-2014, para que se pueda constatar la coherencia de la estrategia de política exterior sugerida. En aspectos tales como la estabilización de las relaciones regionales, la consolidación de la participación en organismos multilaterales y el desarrollo de estrategias conducentes al ingreso a la OCDE, entre otras cosas, debe darse continuidad a las labores adelantadas. Otro importante desafío relacionado con lo que anteriormente se había tocado sobre el conflicto interno, radica en desarrollar las capacidades para vincular los temas de política interna con los de política exterior. Aquello de las denominadas variables "inter-mésticas" es cada vez más una necesidad en el ejercicio internacional de las naciones.

JG: ¿Qué estrategias debe llevar a cabo el gobierno para que Colombia pueda mostrarse como un país relevante en el ámbito internacional?

LFVA: Antes que plantear una estrategia para adquirir tal relevancia, debería plantearse el manejo coherente y consecuente de la política exterior, para que ésta alcance el carácter de lineamiento estatal, amparado en unos objetivos claramente nacionales. La estructuración de la política exterior, respaldada en la institucionalidad creada para tal efecto, debe ser una 
condición. Mientras se siga dependiendo de las decisiones de unos pocos, que además resultan ser decisiones tomadas bajo la presión e incidencia de élites dominantes, las relaciones internacionales del país no van a evolucionar lo suficiente como para permitir algún relativo protagonismo regional, ni mucho menos global.

JG: Finalmente, en términos de investigación académica, ¿Cuáles son los retos más grandes que enfrenta el campo de las relaciones internacionales actualmente en Colombia?

LFVA: Las relaciones internacionales han tenido una tradición en América Latina que está asociada al hecho de ser una disciplina ajena, prestada si se quiere, por las élites del pensamiento internacional dominante. Colombia no está por fuera de dicha tendencia. En el país escasamente se habla de la disciplina desde los años 90, cuando a raíz de un seminario desarrollado por la Universidad de los Andes se empezó a generar algún ruido al respecto. Las Universidades que poseen los programas de RRII están en su mayoría (por no decir que todas) en Bogotá, por lo que la oferta académica en el país resulta supremamente reducida a un ámbito geográfico.
Ahora bien, ya se han venido dando algunos avances importantes en la medida en que se ha incluido en los Congresos de ACCPOL un capítulo de RRII, por ejemplo. También con la concreción de Redintercol, que es la Red Colombiana de Relaciones Internacionales, se ha querido dar un paso más adelante en el desarrollo y consolidación de una comunidad académica sobre temas internacionales. También hay ya algunos avances importantes en materia de publicaciones, puesto que algunas de estas revistas ya han alcanzado un alto nivel de indexación internacional.

Finalizaría señalando que los retos para el campo de las RRII están orientados todos a mantener la evolución dada en los últimos 15 años. Para las instituciones es vital fortalecer su cuerpo profesoral con individuos formados en investigación, fundamentalmente en las universidades que presentan mayor rigurosidad en el desarrollo de sus programas. Así mismo, es muy importante que se sigan desarrollando eventos académicos en los que se exhiban los resultados de investigación alcanzados por los profesores e investigadores del área. 